\title{
Thickness and marking quality of different occlusal contact registration strips
}

\author{
Maria Fernanda de Souza Mauá Serapião TOLEDO', Renata Pilli JÓIAS², Yves Santini MARQUES-IASI', Ana Christina \\ Claro NEVES ${ }^{3}$, Sigmar de Mello RODE ${ }^{4}$
}

\author{
1- Private Practice, São Paulo, SP, Brazil. \\ 2- Department of Bioscience and Oral Diagnosis, Oral Biopathology Graduate Program, School of Dentistry, Science and Technology Institute, Univ. Estadual \\ Paulista (UNESP), São José dos Campos, SP, Brazil. \\ 3- Department of Dentistry, University of Taubaté (UNITAU), Taubaté, SP, Brazil. \\ 4- Department of Dental Materials and Prosthodontics, School of Dentistry, Science and Technology Institute, Univ. Estadual Paulista (UNESP), São José \\ dos Campos, SP, Brazil.
}

Corresponding address: Sigmar de Mello Rode - Departmento de Materiais Odontológicos e Prótese - Instituto de Ciência e Tecnologia - Univ. Estadual Paulista (UNESP) - R. Eng Francisco José Longo, 777 - Jardim São Dimas - São José dos Campos - SP - Brazil - 12245-000 - e-mail: sigmarrode@uol.com.br

Submitted: March 25, 2014 - Modification: June 10, 2014 - Accepted: September 9, 2014

\section{ABSTRACT}

\begin{abstract}
bjectives: Evaluate the thickness and the marking quality of different occlusal contact registration strips (OCRS) and a possible correlation between them. Material and Methods: The following OCRS were selected: Accufilm II, BK20, BK21, BK22, BK23, BK28, and BK31. The thickness was measured in three points of the OCRS with an electronic measuring device (TESA), and the mean was calculated. To produce the marks on the strips, composite resin specimens were adapted to a universal testing machine (Versat 2000) with $40 \mathrm{kgf}$ load cell at a speed of $1.0 \mathrm{~mm} / \mathrm{min}$. The mark images were photographed with a stereoscopic microscope (Stemi SV11) and processed and analyzed by the 550-Leica Qwin ${ }^{\circledR}$ analyzer. Results: Values $(\mu \mathrm{m})$ found in the $1^{\text {st }}$ and $2^{\text {nd }}$ thickness measurements were: Accufilm II - 16.4 and 14.2; BK20 - 10.0 and 8.1; BK21 - 9.5 and 8.0; BK22 - 9.7 and 8.7; BK23 - 9.8 and 7.9; BK28 - 12.8 and 10.0; and BK31 - 8.4 and 8.0, respectively. The mean $\left(\mathrm{mm}^{2}\right.$ ) values found in the mark areas were: Accufilm II - 0.078; BK20 - 0.035; BK21 - 0.045; BK22 - 0.012; BK23 - 0.022; BK28 - 0.024; and BK31 - 0.024. The results were submitted to the Kruskal-Wallis $(p<0.05)$ and Pearson's correlation tests. Conclusions: Only in the $2^{\text {nd }}$ measurement, the OCRS thickness observed was similar to the value indicated by the manufacturers; the Accufilm II and the BK28 strips showed the better marks; and no correlation was found between the thickness and the marking area.
\end{abstract}

Keywords: Dental occlusion. Occlusal adjustment. Prosthodontics. Dentistry. Oral diagnosis.

\section{NTRODUCTI ON}

With a view to the preservation of dental, periodontal, articular, and muscular health, it is important to observe adequate static and functional occlusion. In static occlusion, simultaneous, bilateral, and homogeneous contacts should be observed between the maxillary and mandibular teeth; absence of rotation and crowding, tight contacts, proper mesio-distal crown angulation and labio-lingual crown inclination, and moderate overjet and overbite ${ }^{1}$. With regard to functional movements of the jaw, canine guidance without interference or premature contacts on both sides and mutually protected occlusion in the protrusive position are required ${ }^{8}$.

I nappropriate occlusal contacts can be triggered by occlusal interferences, serious discrepancies between centric relation (CR) and centric occlusion (CO), loss of teeth, absence of tight contacts, malocclusion, bruxism, loss of vertical dimension, and increased tooth mobility, among other factors.

In the presence of occlusal disharmony associated with temporomandibular joints (TMJ) physiological and functional imbalance, some stress may trigger various deleterious effects, such as tooth mobility and/or sensitivity, periodontal problems, incoordination or hyperfunction of the masticatory muscles, and lateral occlusal loads, among others ${ }^{3,5,7}$. 
Having established the importance of balanced and harmonious occlusion, it is important for dentists to perform routine analysis of dental occlusion and check contact between the maxillary and mandibular arches. For this purpose, occlusal contact registration strips (OCRS) are recommended for recording occlusal contacts, as an aid to diagnosis, enabling proper treatment planning and minimizing or solving occlusal disorders.

There is a large number of materials available for checking and defining occlusal contacts, such as waxes, carbon paper, metal sheets, plastic sheets, silk strips, as well as different methods to measure these contacts. Among these methods, there are both qualitative and quantitative types; thus, the former type is used to locate the contact points, and the latter, to set their sequence and density. The qualitative method requires the same materials as those indicated for the verification and identification of contacts, whereas in the quantitative method, the "T-scan" and "photo-occlusion" are used".

Some factors need to be considered in choosing the most appropriate OCRS for checking occlusal contacts, such as thickness, strength, and elasticity ${ }^{6}$. If the OCRS is extremely thick, it may interfere with the patient's occlusal perception, which ranges from 12.5 to $100 \mu \mathrm{m}$. Resistance refers to the OCRS ability to withstand the moist oral environment without impairing its ability to define the occlusal contacts. The elasticity is the OCRS ability to stretch without tearing when it is pulled out of the oral cavity after checking the contact ${ }^{4}$.

It is recommended that the OCRS should be used only once to mark the contacts, because, otherwise, the number of contacts may decrease due to the material deterioration ${ }^{9}$.

Carbon paper is a widely used material because of its low cost and ease of use of its width, thickness and the type of ink on its surface are related to the marks it produces on the tooth surface. However, some unfavorable aspects have been perceived, such as moisture failing (saliva), low elasticity, thin base, and relatively inflexible base material. All these factors may result in large numbers of pseudocontacts ${ }^{9}$.

Silk strips have been considered the best material for this purpose due to their soft texture, which does not produce pseudocontacts ${ }^{2}$, although they could be damaged by saliva. It is advisable to store silk strips in a cool and closed place 9 .

Plastic strips are thinner materials that provide more accurate occlusal contact registrations, which are more easily visualized. However, as they are not capable of registering low-pressure situations (straight and shiny surfaces), they need to be used under strong pressure.

Based on the lack of studies evaluating the accuracy of materials used to mark occlusal contacts, the objectives of this study were: 1 evaluate the thickness of different OCRS; 2 - assess the quality of the marking each OCRS produces; and 3 - correlate the OCRS thickness and the quality of marks.

\section{MATERIAL AND METHODS}

\section{Sample}

Samples of seven types of OCRS $(n=10)$ were selected (Figure 1) and standardized to a length of $5.5 \mathrm{~cm}$ and width of $3.0 \mathrm{~cm}$.

\section{Measuring the OCRS thickness}

The thickness evaluation was performed three times at three points, one central and the others at each extremity, using the electronic measuring device TESA (TESA, Microntesa, Kempton Park,

\begin{tabular}{|c|c|c|c|}
\hline Kind & Brand & Thickness & Color \\
\hline Accufilm II & $\begin{array}{c}\text { Parkell, Farmingdale, N.Y., } \\
\text { USA }\end{array}$ & $8 \mu \mathrm{m}$ & Black/red \\
\hline $\begin{array}{c}\text { BK 20- Folha de Articulação } \\
\text { Arti-fol ultrafina }\end{array}$ & Bausch, Nashua, NH, USA & $8 \mu \mathrm{m}$ & $\begin{array}{c}\text { Black } \\
\text { (single-side) }\end{array}$ \\
\hline $\begin{array}{c}\text { BK 21- Folha de Articulação } \\
\text { Arti-fol ultrafina } \\
\end{array}$ & Bausch, Nashua, NH, USA & $8 \mu \mathrm{m}$ & $\begin{array}{c}\text { Red } \\
\text { (single-side) }\end{array}$ \\
\hline $\begin{array}{c}\text { BK 22- Folha de Articulação } \\
\text { Arti-fol ultrafina }\end{array}$ & Bausch, Nashua, NH, USA & $8 \mu \mathrm{m}$ & $\begin{array}{c}\text { Green } \\
\text { (single-side) }\end{array}$ \\
\hline $\begin{array}{c}\text { BK 23- Folha de Articulação } \\
\text { Arti-fol ultrafina }\end{array}$ & Bausch, Nashua, NH, USA & $8 \mu \mathrm{m}$ & $\begin{array}{c}\text { Blue } \\
\text { (single-side) }\end{array}$ \\
\hline $\begin{array}{l}\text { BK 28- Folha de Articulação } \\
\text { Arti-fol ultrafina }\end{array}$ & Bausch, Nashua, NH, USA & $12 \mu \mathrm{m}$ & Black/red \\
\hline $\begin{array}{c}\text { BK 31- Arti-fol Metallic Folha } \\
\text { de Shimstock }\end{array}$ & Bausch, Nashua, NH, USA & $12 \mu \mathrm{m}$ & $\begin{array}{c}\text { Red } \\
\text { (single-side) }\end{array}$ \\
\hline
\end{tabular}

Figure 1- Occlusal contact registration strips (OCRS) used to record occlusal contacts 
Gauteng, South Africa) with a clock micrometer (reading scales: $300 \mu \mathrm{m}, 100 \mu \mathrm{m}, 30 \mu \mathrm{m}, 10$ um, $3 \mu \mathrm{m}$ ) and a feeler, in order to obtain the mean thickness values.

For the thickness evaluation, each OCRS was placed between the feeler and a flat table, and the reading scale was set to zero, so that all the measurements were performed at the same point, using the same references for standardization.

A universal testing machine (Versat 2000, Panambra Zwick/Roell, São Bernardo do Campo, SP, Brazil) with a $40 \mathrm{kgf}$ load cell was used to make the OCRS marks on the specimens. After this, the second thickness measurement was evaluated at the same point that had received the fist puncture load, following exactly the same protocol as described in the first measurement.

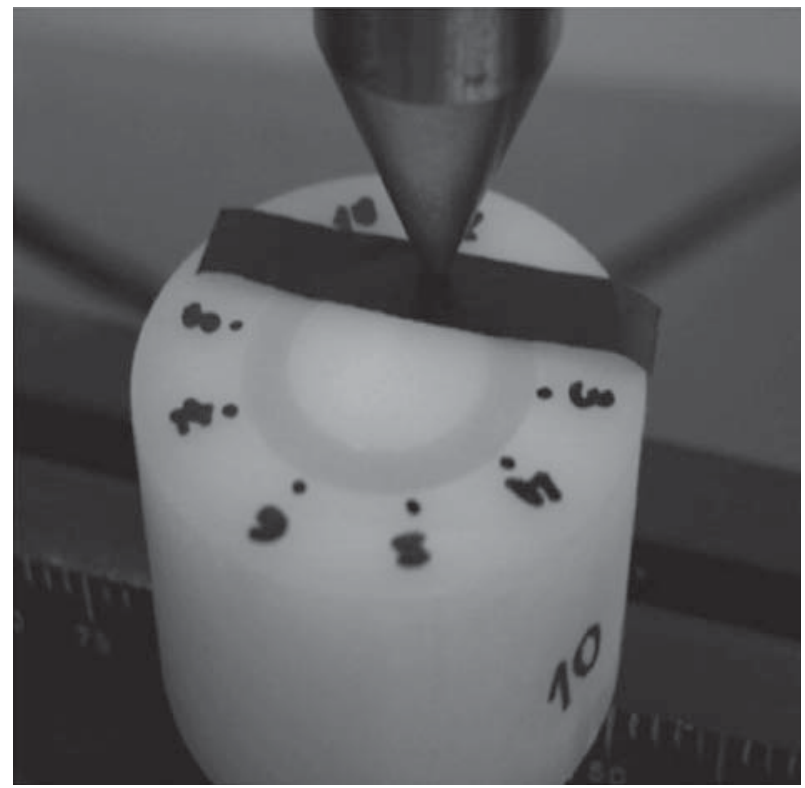

Figure 2- Contact marks

\section{Specimen}

The specimens consisted of nylon devices measuring $3 \mathrm{~cm}$ in height $\times 5 \mathrm{~cm}$ in diameter, with a central channel of $3 \mathrm{~cm}$ diameter $\times 5$ $\mathrm{mm}$ in width $\times 2 \mathrm{~mm}$ in depth. To obtain the ten specimens, the cylinder was filled with composite resin Filtek Z350 (3M, ESPE, Sumaré, SP, Brasil) using the incremental technique and 30-second polymerization (Ultralux, Dabi Atlante, Ribeirão Preto, SP, Brazil). Decreasing granulations of water abrasive papers were used to polish the specimens.

\section{Marking the contacts}

The compression test was also performed with the 2000 Versat machine, using a $500 \mathrm{~kg}$ load cell and $40 \mathrm{kgf}$ at a speed of $1 \mathrm{~mm} / \mathrm{min}$. A stainless steel ball $2.5 \mathrm{~mm}$ in diameter was coupled to the top of the machine, to make the OCRS puncture toward the specimen.

In the specimens, there were predetermined areas where the contacts would be distributed on the surface of the composite resin to enable the area to be identified and measured. There was an interval with a minimum distance of $6.5 \mathrm{~mm}$ between the marks (Figure 2).

The bilateral surface OCRS were tested on the same side in the first five specimens and on the opposite side in the next five specimens.

\section{Scanning and image analysis}

The marks were photographed with a stereoscopic microscope at 2.5x magnification (Stemi SV11, Zeiss, Oberkochen, Baden-Württemberg, Germany), and the images were processed with the Qwin ${ }^{\circledR}$ Leica 550 (Leica Microsystems I mage Solutions SA, Wetzlar, Hessen, Germany), in which the higher intensity pixels were recognized by a software and highlighted in red, and the area around them was also grouped. Finally, for each specimen, the marking area was calculated in $\mathrm{mm}^{2}$ (Figures $3 \mathrm{a}, \mathrm{b}$ ).

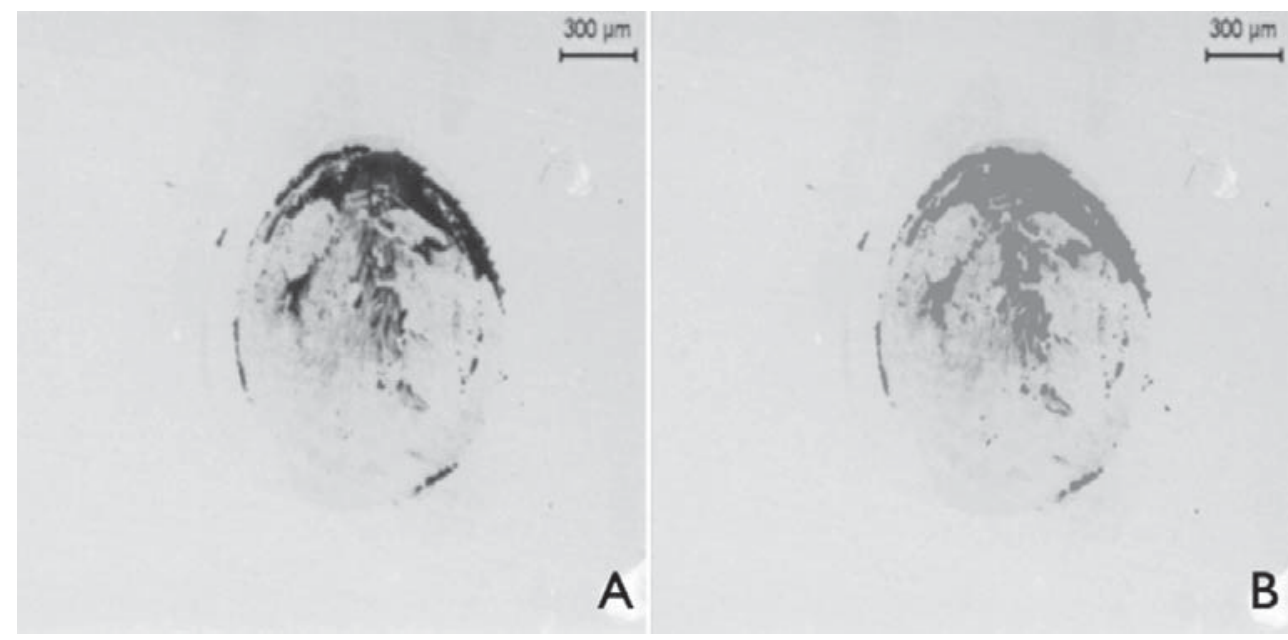

Figure 3- Accufilm II mark before and after treatment of the area by Leica analyzer 


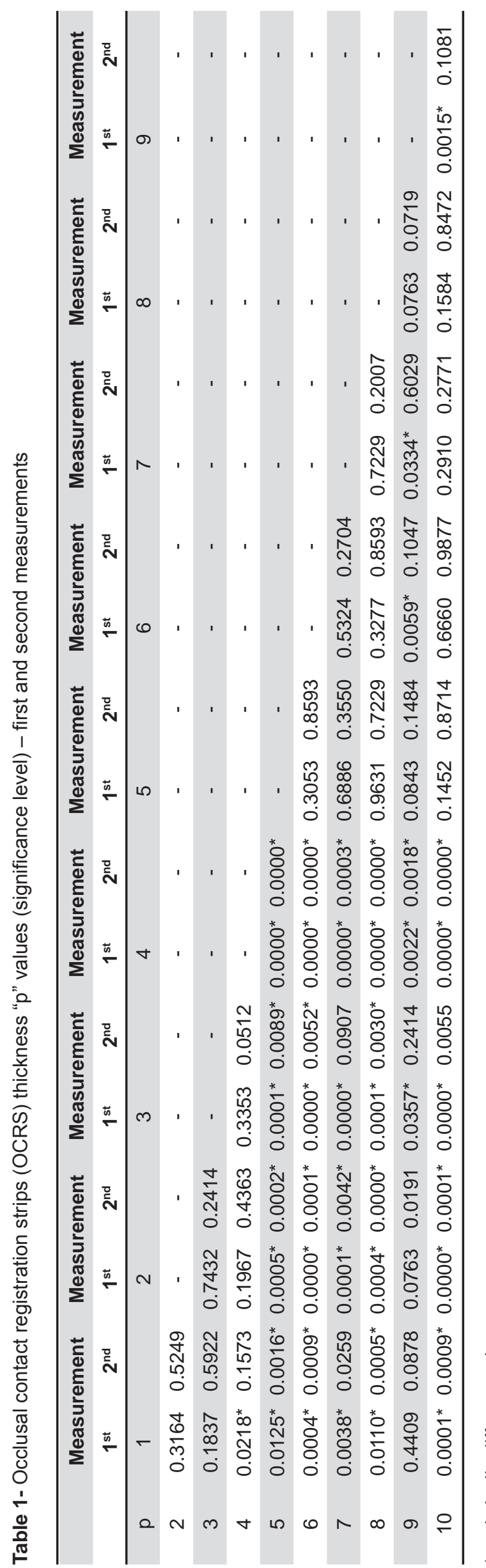

\section{Statistical analysis}

Data analysis was carried out by means of the D'Agostino normality test, and because the data did not adhere to the normal curve, the nonparametric Kruskal-Wallis test was applied at a level of significance of $5 \%$. ANOVA for two paired samples was used to visualize the difference that occurred between the first and the second thickness measurement (significance level of $5 \%$ ). The Pearson correlation test was applied in order to find out whether there was any possible correlation between the OCRS thickness and the area of the mark.

\section{RESULTS}

The thickness values obtained in the first and second measurements (Table 1 ) were statistically different.

ANOVA showed that the " $p$ " values were lower than 0.05 in all groups (Table 2), meaning that there were significant changes in all the OCRS after the marks were performed.

The Pearson correlation coefficient ( $r$ Pearson $0.3495)$ showed no correlation between the OCRS thickness and the area of the mark. In the diagram (Figure 4), homogeneous dispersion of the points in the two OCRS thickness tracks can be observed. Thus, this data, combined with the low " $r$ " value, indicates that there is no correlation.

\section{SCUSSI ON}

The interest in investigating the OCRS was aroused due to the lack of research and articles related to this topic. There have been few studies that have tested the accuracy and reliability of these materials and concerning the techniques used for marking occlusal contacts, considering that the occlusal analysis made with these OCRS is of paramount importance in many dental procedures. It is well known that the effect of the pressure area on the OCRS is influenced by the resilience and viscosity of the periodontal ligament, but this in vitro study provides an initial understanding regarding the OCRS quality of marking since the load applied is patterned.

Samples of the OCRS selected for the survey presented two types of base material (silk and metal), four pigment colors (blue, black, green, and red) and bilateral staining (black/red) when considering Accufilm II and BK 28.

Depending on the OCRS physical properties (thickness, plastic deformation and resistance), there may be interference in the marking processes; thus, a product may mark a real contact area; produce a false mark, or mark an area that has no occlusal contact ${ }^{10}$. Studies have shown that the 
Table 2- Occlusal contact registration strips (OCRS) thickness "p" values (significance level) - marking area

\begin{tabular}{cccccccccc}
\hline $\mathbf{p}$ & $\mathbf{1}$ & $\mathbf{2}$ & $\mathbf{3}$ & $\mathbf{4}$ & $\mathbf{5}$ & $\mathbf{6}$ & $\mathbf{7}$ & $\mathbf{8}$ & $\mathbf{9}$ \\
\hline 2 & 0.1607 & - & - & - & - & - & - & - & - \\
3 & 0.3987 & 0.5763 & - & - & - & - & - & - & - \\
4 & 0.7933 & 0.254 & 0.5606 & - & - & - & - & - & - \\
5 & $0.005^{*}$ & 0.1607 & $0.0498^{*}$ & $0.011^{*}$ & - & - & - & - & - \\
6 & 0.0744 & 0.7028 & 0.3471 & 0.128 & 0.3071 & - & - & - & - \\
7 & $0^{*}$ & $0.0008^{*}$ & $0.0001^{*}$ & $0^{*}$ & 0.0516 & $0.003^{*}$ & - & - & - \\
8 & $0.0003^{*}$ & $0.0262^{*}$ & $0.0054^{*}$ & $0.0008^{*}$ & 0.4117 & 0.0655 & 0.2605 & - & - \\
9 & 0.3108 & 0.6971 & 0.8654 & 0.4524 & 0.0731 & 0.4409 & $0.0002^{*}$ & $0.009^{*}$ & - \\
10 & $0.0004^{*}$ & $0.035^{*}$ & $0.0077^{*}$ & $0.0012^{*}$ & 0.4807 & 0.0843 & 0.2146 & 0.908 & $0.0125^{*}$ \\
\hline
\end{tabular}

*statistically different values

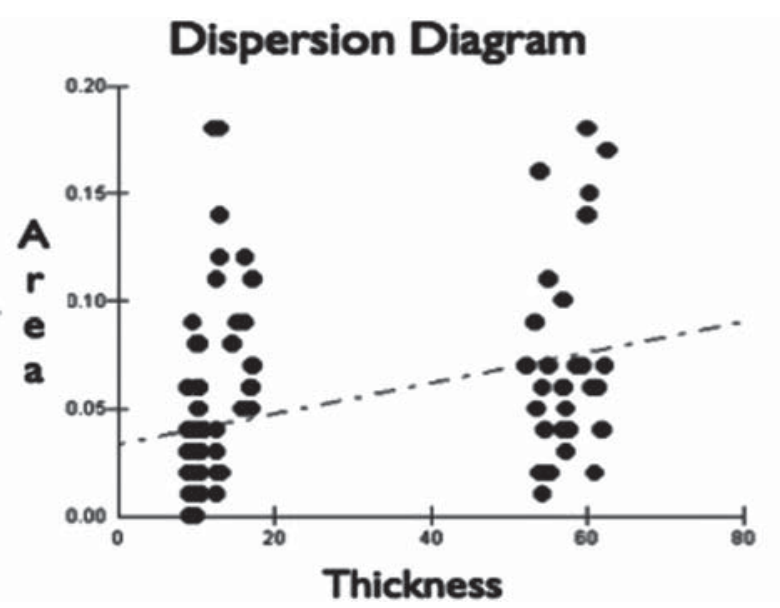

Figure 4- Pearson's correlation test dispersion diagram thickness $\mathrm{x}$ marking area

presence of moisture (saliva) in the oral cavity negatively affects the base of paper strips, causing tearing and/or fragmentation ${ }^{4,9}$, or distortion of contact marks ${ }^{10}$, in addition to showing that there is a difference between the number of contacts marked on a dry and on a wet tooth surface ${ }^{9}$. Therefore, the survey was conducted in the dry laboratory in order to eliminate the moisture effect (saliva), and the number of punctures made by each strip when marking the occlusal contacts was limited and constant.

Verification of the OCRS thickness showed that only the second measurement values were similar to those reported by manufacturers.

When checking the ink distribution pattern on the composite resin and comparing the uniformity of the distribution of the marks on the specimens, it was observed that the strips that produced more uniform marks were Accufilm II and BK28. It should be noted that the color of the pigment changes the OCRS quality or capacity of marking contacts, so that the BK23 (green pigment) produced very small marks and detached the least amount of ink.

The thickness and the material of the film, and the marker substance affected the size of the mark. The red OCRS registered comparatively larger marks than the other strips of similar thickness, while thinner polyester plastic strips produced smaller marks than the paper or silk types ${ }^{9}$.

The correlation between the OCRS thickness and the area of the mark, by the Pearson's correlation test, showed that both the thicker and thinner OCRS produced larger and smaller marks, so there was no correlation between the thickness measurement and the marking area. Thus, based on the results, it is not possible to affirm that the thicker the strip the bigger the mark produced, in disagreement with other authors ${ }^{2,9}$.

Although the methodology of this research is very similar to that described in the literature ${ }^{9}$, the results were not coincident. The two methods are similar, but with some changes that could have caused this difference. A possible hypothesis might be: the surface material marking, the marking analysis, the number of markings of each OCRS on the specimens, and the types of OCRS studied.

\section{CONCLUSION}

It was concluded that only in the second measurement the OCRS thickness observed was similar to the value indicated by the manufacturers; the Accufilm II and the BK28 strips showed the most accurate markings; and no correlation was found between the thickness and the marking area. 


\section{REFERENCES}

1- Andrews LF. The six keys to normal occlusion. Am J Orthod. 1972;62(3):296-309.

2- Carossa S, Lojacono A, Schierano G, Pera P. Evaluation of occlusal contacts in the dental laboratory: influence of strip thickness and operator experience. Int J Prosthodont. 2000; 13(3): 201-4.

3- Dworkin SF, LeResche L. Research diagnostic criteria for temporomandibular disorders: review, criteria, examinations and specifications, critique. J Craniomandib Disord. 1992;6(4):301-55. 4- Halperin GC, Halperin AR, Norling BK. Thickness, strength, and plastic deformation of occlusal registration strips. J Prosthet Dent. 1982;48(5):575-8.

5- Maixner W, Greenspan JD, Dubner R, Bair E, Mulkey F, Miller V, et al. Potential autonomic risk factors for chronic TMD: descriptive data and empirically identified domains from the OPPERA casecontrol study. J Pain. 2011;12(11 Suppl):T75-91.
6- Millstein P, Maya A. An evaluation of occlusal contact marking indicators. A descriptive quantitative method. J Am Dent Assoc. 2001; 132(9): 1280-6.

7- Pullinger AG, Seligman DA, Gornbein JA. A multiple logistic regression analysis of the risk and relative odds of temporomandibular disorders as a function of common occlusal features. J Dent Res. 1993; 72(6): 968-79.

8- Roth RH. Functional occlusion for the orthodontist. J Clin Orthod. 1981; 15(1): 32-40,44-51.

9- Saraçoğlu A, Özpinar B. In vivo and in vitro evaluation of occlusal indicator sensitivity. J Prosthet Dent. 2002;88(5):522-6. 10- Schelb E, Kaiser DA, Brukl CE. Thickness and marking characteristics of occlusal registration strips. J Prosthet Dent. 1985; 54(1): 122-6. 